American Journal of Applied Sciences 8 (5): 481-485, 2011

ISSN 1546-9239

(C) 2010 Science Publications

\title{
Determinants of Attitude towards Information and Communication Technology Usage among Rural Administrators in using Structural Equation Modeling
}

\author{
Jeffrey Lawrence D’Silva, Bahaman Abu Samah, Hayrol Azril Mohamed Shaffril, \\ Musa Abu Hassan and Muhamad Badsar \\ Laboratory of Rural Advancement and Agriculture Extension, \\ Institute for Social Science Studies, Universiti Putra Malaysia, Putra Infoport, \\ 43400 Serdang, Selangor Darul Ehsan, Malaysia
}

\begin{abstract}
Problem statement: Village Development and Security Committee members play a vital role in enhancing the village development programs in Malaysia and ICT is deemed as an important mechanism to further boost rural development. But do the rural community in Malaysia especially their leaders have a positive attitude towards it? Hence, this study is designed to identify the constructs that significantly influence the attitude of Village Development and Security Committee members in using ICT. Approach: This is a quantitative study where a total of 240 respondents have been selected based on the stratified random sampling done. AMOS and SPSS were used to gain the required analyses. Results: The structural equation modelling showed that there were three constructs that significantly predict the attitude and these constructs were perceived ease of use, perceived usefulness and job relevance. Conclusion/Recommendation: It is recommended that more technology investment in the form of providing ICT facilities and trainings should be made by the government to encourage the development of a positive attitude among VDSC members. The findings of this study would be useful for policy makers to further boost the usage of ICT in rural areas.
\end{abstract}

Key words: Village development, communication technology, rural development, structural equation modelling, stratified random, measurement model, Information Technology (IT), security committee

\section{INTRODUCTION}

Information and Communication Technology or ICT is an important catalyst nowadays for the purpose of development. According to Frimpong-Kwapong (2009), the widely used acronym ICT has been understood to cover a multitude of equipment, softwares and services. ICT can be comprehended as technologies that facilitate communication and the processing and transmission of information by electronic means. This definition encompasses the full range of ICTs, from radio and television to telephones (fixed and mobile), computers and the Internet. ICT includes a number of components that provide an array of advantages and the advance in the word processing software, spreadsheets, computer aided desing and relational database technologies provide much benefit to mankind (Iskandarani, 2008). Musa (2010) clarified ICT as a combination of two concepts namely technology and communication. Technology is a tool or software used to do or construct something. It can be assistance to those who use it, save time and cost, efficient and secured. Information Technology (IT) refers to method, tools and software involved in the process of developing, gathering and processing, administering, disseminating and recording unlimited information. People always see ICT as computer and internet due to its ability in running all of the tasks mentioned above. However, other ICT tools such as television, radio and newspaper also have the same capability. Since media communication, communication technology and information technology in many issues are referred to the same thing, thus the concept of Information and Communication Technology has been accepted and used.

In Malaysia, ICT has been persistently utilized as an effective mechanism to develop the rural community and areas. The Malaysian government has

Corresponding Author: Jeffrey Lawrence D’Silva, Laboratory of Rural Advancement and Agriculture Extension,

Institute for Social Science Studies, Universiti Putra Malaysia, Putra Infoport, 43400 Serdang, Selangor Darul Ehsan, Malaysia Tel: 603-89471862 Fax: 603-89471856 
initiated a number of ICT programs and agendas that are allocated especially for the rural people. Since the 7th Malaysian Plan till the 10th Malaysian Plan, many ICT projects were implemented to boost the livelihood of the rural people.

Malaysian government's efforts in bringing the impact of ICT to the community: The sixth challenge in the Malaysian government's effort to drive this country as a developed country in 2020 is to create a scientific and progressive community which is able to change and look forward not just as technology users but also as the contributors to future scientific and technology civilization. To achieve this, the government has planned a number of activities and allocated budget on it. For example, in the Ninth Malaysian Plan, the government has allocated RM12.9 billion for ICT programs and projects. From this amount, $20 \%$ has been prepared specifically for the purpose of reducing the digital divide that occurs between the urban and rural areas. On top of it, projects such as Rural Internet Centers and Computer Literacy Centers have been launched.

The involvement of the local rural community on such programs is essential to boost their knowledge and skills in ICT. Recently, the government has strengthened the ICT development in Malaysia when the National Broadband Initiative (NBI) has been launched. The main objective of NBI is to encourage community to posses and use the broadband services. They also have aired an IT song entitled "One house one computer". Besides, tax rebate for buying computer has been given and low interest on loan made for buying a computer also has been activated (Bahaman et al., 2011). These steps have been followed by private sectors by establishing a number of cyber cafés for public. Interestingly, NGO's in Malaysia also are involved to ensure the public have been provided with the opportunity to be exposed to the benefits of ICT. As an example in Selangor, they have Selangor IT Club, in Malacca, the state government has established ICT program for retirees and KETENGAH in Terengganu has introduced E-Community (Bahaman et al., 2011).

On top of it, other ICT initiatives from the government such as Rural Internet Center, Rural Info Center, National Broadband Initiatives, National Information Technology Agenda, Multimedia Universiti and Multimedia Super Corridor have been introduced. Recently, ICT was selected as one of the NKEAs (one of the 12 identified National Key Economic Areas designed to build the foundation of 10th Malaysian Plan).
Without doubt, one of the dominant forces in the rural community are the Village Development and Security Committee (VDSC) members and it is indeed pertinent that VDSC members should be ready to adopt and use ICT as it will go a long way in helping Malaysia to realize the principles attached in Vision 2020.

Attitude towards ICT usage: There are abundance of existing studies that have been accomplished to discover the adoption and of ICT among the rural leaders and the community (Bahaman et al., 2011). Namdarian (2008) identified that most of the rural leaders that posses a positive attitude use ICT daily and majority of them are compatible in using ICT which prove to ease them in their daily works.

According to Horne (1985) attitude is defined as "a mental and neural state of readiness, organized through experience. Exerting a directive or dynamic influence upon the individual's response to all objects and situations with which it is related". On the other hand, Breckler and Wiggins (1989) claimed that attitude can be constructed on the individual's degree of like or dislike towards something. Persistently attitude will produce either positive or negative views towards a person, place, thing or event and without doubt a positive attitude is an essential instrument for ICT usage. Shiro (2008) has concluded that rural view ICT as an important development tools and they have a positive attitude towards ICT. However, their limited ICT skills and knowledge prohibit them from using ICT effectively and continuously. Continuous and frequent ICT usage is important to build a positive attitude towards ICT usage. Continuous and frequent usage of ICT will make people realize that ICT is helpful and beneficial to them thus creating a positive attitude towards ICT usage. In another research, Zhang and Aikman (2007) have concluded that attitude can be a mediator on the role of attitude toward object on behavioral intention. In this case, it can be understood that a positive attitude toward a particular ICT will lead potential users especially the rural community to decide to accept or use the ICT.

Having witnessed a huge commitment by the government to encourage on the usage of ICT, does the rural community especially their leaders who are VDSC members use ICT and more importantly do they have a positive attitude towards ICT? A thorough search of the existing literature showed that there a number of factors that are used to explain the relationship between attitude and ICT usage. However, this study would like to specifically focus on six variables that have the potential to influence attitude towards ICT usage which are selfefficacy, perceived usefulness, perceived ease of use, 
Am. J. Applied Sci., 8 (5): 481-485, 2011

subjective norm, compatibility and job relevance. Many previous studies have found the effects of self efficacy on ICT usage (Techatassanasoontorn and Tanvisuth, 2008), perceived usefulness and perceived ease of use (Adeosun et al., 2009), compatibility (Al-Ghaith et al., 2010), job relevance (Joseph and Andrew, 2007) and subjective norm (Pee and Kankanhalli, 2010) on ICT usage. But do all of these factors have an influence on attitude towards ICT usage? Hence, this question will fulfill the main objective of this study which is to build a model that explains the factors that determine the attitude towards ICT usage among VDSC members.

\section{MATERIALS AND METHODS}

A quantitative method was used in this research. This study was conducted for 18 months beginning from October 2009 and ended in March 2011. Stratified random sampling method was employed to determine the respondents. Eventually 240 respondents were selected from 24 Village Vision Movement (VVM) villages in Malaysia.

Instrument development: AMOS software was used to conduct the CFA in determining instrument that measure constructs of ICT usage. In CFA analysis, Chi Square, GFA Index Value, CFI and RMSEA were applied. An instrument is considered reliable if the Chi Square value is low and its significance value is high (larger than .05), GFI index and CFI value must be larger than .9 and RMSEA value must be lower than .08 . Analysis conducted involved two phases. For the first phase, it involved testing on model of measurement for each dimension and for the second phase to test on the constructs of ICT usage.

\section{RESULTS}

Before evaluating the fit of structural model, it was necessary to define a measurement model to verify the construct validity of each research instrument. For this purpose, CFA was carried out to determine the degree of model fit, the adequacy of factor loadings and explained variances for the measurement variables. Also the reliability (internal consistency) of each constructs was assessed by Cronbach's alpha.

The results of assess the measurement model indicated that the data fit the model: $\chi^{2}(512)=1461.346$, $\mathrm{p}=0.000 \chi^{2} / \mathrm{DF}=2.854 ; \mathrm{GFI}=0.725, \mathrm{CFI}=0.923, \mathrm{NFI}=$ 0.886 , IFI $=0.923$, TLI $=0.915$, RMSEA $=0.088$. The CFI, IFI and TLI significantly pass its cutoff value (0.9). In addition, The RMSEA was 0.088 , which slightly higher the recommended range (between 0.03 and 0.08 )
(Hair et al., 2006). Thus, the result shows that measurement model has a good fit with the data.

The construct validity of the instrument was also verified in this study, in that all the items had high standardized factor loading on their underlying constructs (values ranged from 0.74-0.97) and were all significant at 0.001 . The convergent validity for all constructs was exceeded the minimum criterion of 0.50 , indicating that the majority of the variance was explained by the constructs.

The measurement reliability was assessed by Cronbach's alpha. The alpha values for six constructs ranged between 0.971-0.995 and since each construct exceeded the minimum requirement of 0.7 , it ensured adequate internal consistency.

The result of assessment of univariate normality in measurement model based on skew and kurtosis criteria within the range of $+/-1.5$ reveals no item to be nonnormal (Hair et al., 2006). Skewness was ranged from $1.019-0.345$ and kurtosis were ranged from -1.4540.116 .

The results of correlation estimates between the constructs in measurement model showed that there were not any problems of multicollinearity between the constructs. The correlation estimates between the constructs ranged between $0.52-0.87$

Correlation analyses: Pearson product-moment correlation was used to examine association between the five factors and attitude towards ICT usage. Based on the obtained results, all of the five factors studied correlate positively with attitude towards ICT usage. It was identified that the magnitude of association between the four factors and attitude towards ICT usage was high and substantial. The factors were self-efficacy $(\mathrm{r}=0.777)$, perceived usefulness $(\mathrm{r}=0.723)$, compatibility $(\mathrm{r}=0.721)$ and perceived ease of use $(\mathrm{r}=$ 0.708). Another factor which was job relevance $(r=$ 0.664) was identified to have a moderate and substantial association.

Structural Equation Modeling (SEM) analyses: Also with the aim of determining the contribution of each construct of independent variable entered in the equation in relation to the dependent variable, the structural equation modeling was used. The results of assessing the structural model fits indicated that the data fit the model with; $\chi^{2}(194)=1461.346, p=0.000$, $\chi^{2} / \mathrm{DF}=2.854 ; \mathrm{GFI}=0.725, \mathrm{CFI}=0.923, \mathrm{NFI}=0.886$, TLI $=0.915$, IFI $=0.923$, RMSEA $=0.088$. The Goodness-of-fit indices of structure model showed that the CFI, TLI and IFI significantly its cutoff value (0.9). In addition, the RMSEA was 0.088 , which is extremely 
close to the recommended range of acceptability (between 0.03 and 0.08 ).

The results also showed that perceived ease of use latent construct (consists of four items) had significant relationship with attitude towards ICT usage) $(\mathrm{B}=$ 0.337 , C.R. $=3.357, p=0.000$ ). It was also identified that perceived usefulness latent construct (consists of seven items) had significant relationship with attitude towards ICT usage $(\mathrm{B}=0.275$, C.R. $=4.508, \mathrm{p}=$ $0.000)$. Similarly, the job relevance latent construct (consists of six items) was found to have significant relationship with attitude towards ICT usage $(\mathrm{B}=$ 0.157, C.R. $=2.547, \mathrm{p}=0.011$ ).

\section{DISCUSSION}

In general, the above results showed that the level of attitude of VDSC members toward the usage of ICT is at a respectable position and they emphasized on the necessity to attend ICT courses and seminars besides having the feeling of being left behind if they do not use ICT. The study also revealed that there are a number of factors that play an important role to enhance the attitude of these members in the usage of ICT and it was identified that the significant predictors of attitude are perceived ease of use, perceived usefulness and job relevance.

It is evident that the VDSC members would have a positive attitude toward ICT once they are convinced that it is easy to be used especially in their administrative matters and the ease to surf the available search engines with its user interface being less sophisticated and this is in line with the outcome of previous studies carried out by Bahaman et al. (2011) and $\mathrm{Hu}$ et al. (2003) on the impact of perceived ease of use on attitude. According to Meso et al. (2005), perceived usefulness and perceived ease of use, greater reliability of the technology and easier access to ICT are among the contributors for greater confidence thus creating a better attitude towards ICT usage. As can be seen from the demographic results of this study, the bulk of the VDSC members are above 40 years of age and many of them have yet to attain tertiary education and thus it is not surprising that they might be apprehensive in using ICT gadgets that are complicated and require much effort. This could be the main reason for the VDSC members to point out that the construct of perceived ease of use as the important factor that influence their attitude towards the usage of ICT.

Many past studies have shown that perceived usefulness has a positive impact on the usage of ICT (Bahaman et al., 2011) and the current study also demonstrated similar results. It is clear that the attitude of VDSC members would be greatly enhanced if they were to experience on the usefulness of the ICT tools that they utilize especially in saving data in a large capacity, enhancing their work productivity and if ICT were able to save space and money. The results obtained further confirmed the fact that the VDSC members would chose to extensively use ICT by possessing a positive attitude once they perceive that the usage of ICT tools help them to ease their burden in running the village activities.

Job relevance is another predictor of attitude towards ICT among VDSC members as being identified in this study and this in tandem with recent studies carried out by Joseph and Andrew (2007). Among others the job of a VDSC member is to promote their village and to implement development programs in their respective village. This study has shown that the level of attitude towards the usage of ICT was further strengthened as the VDSC members had identified that the ICT tools play an important role to lessen the impediment with the numerous jobs that they have in hand.

\section{CONCLUSION}

It is undeniable that rural development is an important element for the well-being of a nation. VDSC members being the frontrunners in the development of rural villages in Malaysia (D'Silva et al., 2009) need to possess a positive attitude in ICT usage so as to ensure that continuous development programs could be implemented in rural areas. This study depicted the importance of the constructs of perceived ease of use, perceived usefulness and job relevance to enhance the attitude of ICT usage among VDSC members. It is recommended that more technology investment in the form of providing ICT facilities and trainings should be made by the government to encourage the development of a positive attitude among VDSC members. The study had noted that VDSC members will be willing to embark on the extensive usage of ICT once they perceive ICT as being useful to them, its' ease of use and its' relevance in reducing burdensome of workload VDSC members need to endure in their respective villages. It is believed that once these strategies can be implemented, it will boost further usage of ICT in rural areas and ensure continuous development in these areas and in the long run it will be able to narrow down the digital divide between the urban and rural areas and reduce poverty and economic disparity in rural areas. 
Am. J. Applied Sci., 8 (5): 481-485, 2011

\section{REFERENCES}

Al-Ghaith, W., L. Sanzogni and K. Sandhu, 2010. Factors influencing the adoption and usage of online services in Saudi Arabia. J. Elect. Inform. Syst. Dev. Countries, 40: 1-32. ISSN: 1681-4835

Bahaman, A.S., M.S. Hayrol Azril, A.H. Musa and D.S. Jeffrey Lawrence, 2011. Can technology acceptance model be applied on the rural setting: The case of village development and security committee in Malaysia. J. Soc. Sci., 7: 113-119. DOI: $10.3844 /$ jssp.2011.113.119

Breckler, S.J. and E.C. Wiggins, 1989. On Defining Attitude and Attitude Theory: Once more with Feeling. In: Attitude Structure and Function, Pratkanis, A.R., S.J. Breckler and A.G. Greenwald (Eds.). Lawrence Erlbaum Associates, Hillsdale, NJ., $\quad$ pp: 466. http://www.questia.com/library/book/attitudestructure-and-function-by-steven-j-breckleranthony-g-greenwald-anthony-r-pratkanis.jsp

D'Silva, J.L., M.S. Hayrol Azril and A.S. Bahaman, 2009. Commitment among Malaysian village administrators in vision village movement. Euro. J. Soc. Sc., 11: 205-214. ISSN: 1450-2267

Frimpong-Kwapong, O.A.T., 2009. Comparing knowledge and usage of ICT among male and female distance learners of an endowed and deprived area in a developing country in Africa. J. Inform. Technol. Educ., 8: 1-17. ISSN: 1547-9714

Hair, J.F., W.C. Black, B.J. Babin, R.E. Anderson and R.L. Tatham, 2006. Multivariate Data Analysis. 6th Edn., Pearson Prentice Hall, ISBN: 0130329290, pp: 899.

Horne, M.D., 1985. Attitudes Towards Handicapped Students: Professional, peer, and parent reactions. 1st Edn., Routledge, ISBN: 0898595843, pp: 265.

Hu, P.J., T.H.K. Clark and W.W. Ma, 2003. Examining technology acceptance by school teachers: A longitudinal study. J. Inform. Manage., 41: 227-241. DOI: 10.1016/S0378-7206(03)00050-8

Iskandarani, M.Z., 2008. Effect of Information and Communication Technologies (ICT) on nonindustrial countries-digital divide model. J. Comput. Sci., 4: 315-319. DOI: 10.3844/jcssp.2008.315.319
Joseph, M.K. and T.N. Andrew, 2007. Convergence opportunities and factors influencing the use of internet and telephony by the rural women in South Africa and India towards empowerment. J. Comput. Sci., 241: 1-20. DOI: 10.1007/978-0-38773697-6_1

Meso, P., P. Musa and V. Mbarika, 2005. Towards a model of consumer use of mobile information and communication technology in LDCs: The case of Sub-Saharan. J. Afr. Inform. Syst., 15: 119-146. DOI: 10.1111/j.1365-2575.2005.00190.x

Musa, A.H., 2010. Information and communication technology and community development. Proceedings of the Paper presented at IPSAS Intellectual Discourse, IPSAS Meeting Room, Oct. 22, University Putra Malaysia, Serdang, Selangor.

Namdarian, I., 2008. Italian rural ICT (computer and Internet): Deployment and availability at farm and e-government level. Proceedings of the Paper Presented at Adoption of ICT Enabled Information Systems for Agricultural Development and Rural Viability-Joint Conference of IAALD, AFITA and WCCA. Oct. 24, Tokyo, Japan, pp: 1-30.

Adeosun, O.O., T.H. Adeosun and I.A. Adetunde, 2009. Strategic application of information and communication technology for effective service delivery in banking industry. J. Soc. Sci., 5: 47-51. DOI: $10.3844 /$ jssp.2009.47.51

Pee, L.G. and A. Kankanhalli, 2010. Bridging the digital divide: Use of public internet kiosk in Mauritius. J. Global Inform. Manage., 18: 15-38. DOI: 10.4018 /jgim.2010091102

Shiro, U., 2008. A case study of DIY ICT. J. Inform., 10: 46-60. DOI: $10.1108 / 14636690810887535$

Techatassanasoontorn, A.A. and A. Tanvisuth, 2008. The integrated self-determination and self-efficacy theories of ICT training and use: The case of the socio-economically disadvantaged. GlobDev 2008. Paper

19. http://aisel.aisnet.org/globdev2008/19

Zhang, P. and S. Aikman, 2007. Attitudes in ICT acceptance and use. J. Hum. Comput. Int., 2550: 1021-1030. DOI: 10.1007/978-3-540-73105-4_112 